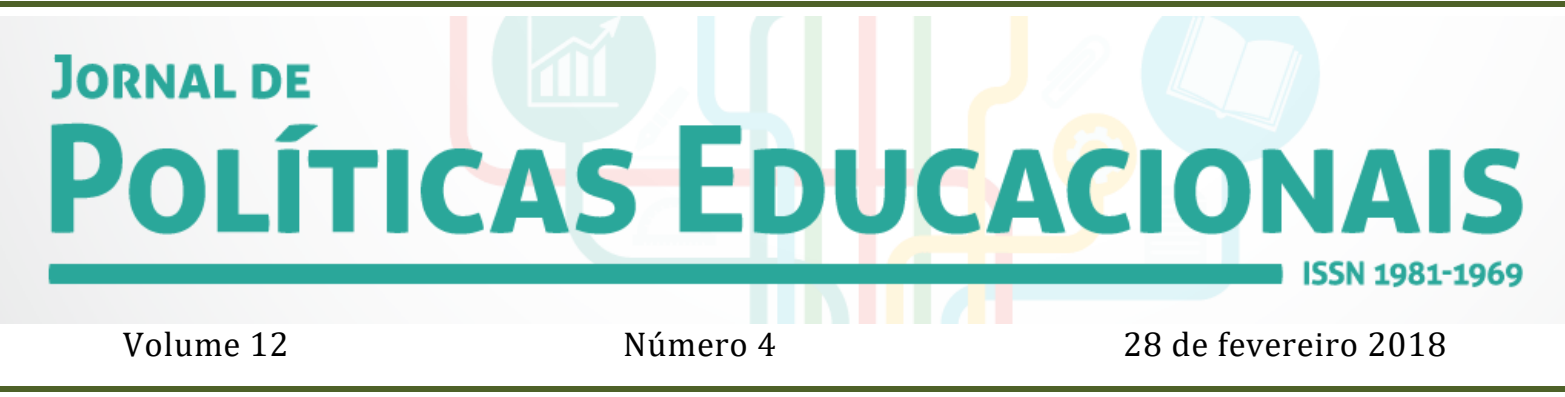

\title{
Profissionalidade docente no breve PNE: formação e valorização
}

\author{
Teaching professionality in the brief PNE: training and valuation
}

Profesionalidad docente en el breve PNE: formación y valorización

\author{
Edite Maria Sudbracke \\ Camila Soares dos Santos ${ }^{2}$ \\ Arnaldo Nogaro ${ }^{3}$
}

Citação: SUDBRACK, E. M.; SANTOS, C. S.; NOGARO, A. Profissionalidade docente no breve PNE: formação e valorização. Jornal de Políticas Educacionais. V. 12, n. 4. Fevereiro de 2018.

http://10.5380/jpe.v12i0.56622

\section{Resumo:}

O ensaio que se anuncia reflete acerca do lugar da formação e da valorização docente no Plano Nacional de Educação (PNE) 2014-2024. 0 texto debate a importância do planejamento educacional de macro espectro na perspectiva proposta pela CONAE de construção de um Sistema Nacional de Educação, enfatizando as metas que abordam diretamente a formação e a valorização profissional docente. 0 ensaio é de cunho teórico, com base em referencial bibliográfico e documentos legais. Pretende reiterar, ainda, a necessidade da resistência do coletivo de educadores para que o que chamamos de Breve PNE não se constitua em década perdida para a educação brasileira.

Palavras-Chave: Formação docente; Valorização; Profissionalização; PNE.

\section{Abstract:}

In this essay we reflect upon the space of education and appreciation of teaching on the National Education Plan (PNE) 2014-2024. The text debates about the importance of educational management of macro spectrum on the perspective of CONAE of building a National Education System, in which we emphasize the

\footnotetext{
${ }^{1}$ Doutora em Educação (2002) pela Universidade Federal do Rio Grande do Sul (UFRGS). Universidade Regional Integrada do Alto Uruguai e das Missões-URI/FW, vínculo institucional desde 1988. http://orcid.org/0000-0002-9591-8038. E-mail: sudbrack@uri.edu.br ${ }^{2}$ Mestra (2017) em Educação (URI - Frederico Westphalen/RS). Professora (2017) do Curso de Pedagogia da UFFS (Chapecó/SC). E-mail: camilafss13@gmail.com

${ }^{3}$ Doutor em Educação (2001) pela Universidade Federal do Rio Grande do Sul (UFRGS). Universidade Regional Integrada do Alto Uruguai e das Missões-URI/FW, vínculo institucional desde 2001. E-mail: narnaldo@uricer.edu.br
} 
goals that approach the appreciation of education and of professional teachers training. The essay has theoretical approach, basing on specific bibliography and legal documents. Besides, it intends to highlight the necessity of resistance from teachers to what is called Brief PNE, facing to not have a new lost decade for Brazilian education.

Keywords: Teacher training; Valuation; Professionalization; PNE.

\section{Resumén:}

El ensayo que se anuncia refleja acerca del lugar de la formación y de la valorización docente en el Plan Nacional de Educación (PNE) 2014-2024. El texto discute la importancia de la planificación educativa de macro espectro en la perspectiva propuesta por la CONAE de construcción de un Sistema Nacional de Educación, enfatizando las metas que abordan directamente la formación y la valorización profesional docente. El ensayo es de cuño teórico, con base en referencial bibliográfico y documentos legales. Pretende reiterar, además, la necesidad de la resistencia del colectivo de educadores para que lo que llamamos Breve PNE no se constituya en década perdida para la educación brasileña.

Palabras clave: Formación docente; recuperación; Profesionalización; PNE.

\section{Para iniciar}

Ainda que o PNE não tenha contemplado a totalidade das proposições da comunidade educativa e dos demais coletivos envolvidos, foi saudado como um marco histórico no Planejamento Educacional Brasileiro, quer pelo seu caráter de participação e mobilização, quer por instituir uma política pública de macro espectro, apontando para avanços há muito desejados, como a emergência de um Sistema Nacional de Educação.

Assumindo função destacada no planejamento educacional, notadamente sob a Coordenação da Conferência Nacional de Educação, ganhou contornos de um planejamento não apenas pontual, mas de médio prazo, atendendo a realidade social em sua dinâmica e em seus limites e contradições.

Sob tal abrigo, o PNE deixou entrever, junto aos setores educacionais uma nesga de esperança, ao enfocar com prioridade em suas metas a questão da valorização e da formação docente, não apenas da formação inicial, mas também da formação continuada, entendendo-a como necessidade vital para o desenvolvimento profissional docente.

No bojo deste compromisso, a perspectiva de que o investimento em educação nos percentuais previstos na Meta 20, ou seja, de 10\% do PIB até o final da vigência do Plano, daria, em tese, a prerrogativa do alcance das metas previstas, entre as quais, as de formação e valorização docente, no entanto, teve vida breve. Os acontecimentos políticos e a crise econômica e financeira jogaram por terra a esperança de que, desta vez um Plano se constituiria de fato em Política de Estado e não em mera carta de intenções sem compromisso. A PEC no 241/55, depois Emenda Constitucional 55/2016, que instituiu um novo regime fiscal, contingenciou as despesas com os encargos sociais e com o funcionalismo e os investimentos públicos, reduziu acintosamente a aplicação de recursos para a educação. 
Os últimos acontecimentos e medidas do governo federal desaquecem o ânimo de quem esperava por políticas arrojadas e ampliação das existentes. A instabilidade em que se encontram Programas como o PARFOR e o PIBID deixam em suspenso o que ocorrerá em termos de políticas de formação de professores. Soma-se a isso o anúncio de que o governo irá propor uma base comum para a formação de professores, além da residência pedagógica. A pergunta que não pode calar é: e a Resolução no 2 de 2015? Integrantes do governo sinalizam em seus discursos que algo está ocorrendo nos bastidores no que tange às políticas de formação de professores. 0 que? Ainda não sabemos.

Sob tal vértice, ainda que um Plano seja, via de regra, o resultado de embates desencadeados por diferentes visões de sociedade e educação, o mesmo configura-se como um sinalizador de um raro momento na história educacional brasileira. Para Dourado (2010, p.269), compreender

[...] os nexos institucionais de implementação de políticas educacionais, por meio de uma política pública, no caso o PNE, implica destacar que as imbricações entre a realidade social dinâmica e os atores sociais são permeadas por categorias analíticas (teórico-conceituais) e procedimentos políticos (fins visados), cuja materialização se efetiva na intersecção entre regulamentação, regulação e ação política, marcados por disputas que traduzem os embates históricos entre as classes sociais e, ao mesmo tempo, os limites estruturais que demarcam as relações sociais capitalistas.

Partimos do pressuposto de que o PNE 2014-2024 representouum divisor de águas no planejamento da educação brasileira, sobretudo, no campo das políticas educacionais. Investigar o PNE é analisar uma política pública que tem assumido posição de destaque em debates educacionais, principalmente na trajetória da Conferência Nacional de Educação (CONAE - 2010/2014) a qual demarcou substantivamente a importância do planejamento da educação, na medida em que faz menção ao papel relevante para a construção de um Sistema Nacional de Educação.

A história do planejamento educacional em nosso país é marcadapor disputas entre diferentes projetos, com concepções distintas sobre o papel do Estado e do próprio planejamento, da relação entre os entes federados e da lógica de gestão e organização (DOURAD0, 2011). No atual cenário, o financiamento e as atribuições do estado em relação à educação retornam ao debate com destacada veemência, notadamente pela influência e interferência de grupos econômicos junto a setores e instâncias do governo federal e do Conselho Nacional de Educação. 
O planejamento educacional situa-se numa perspectiva de construção em rede e, por estar constituído dessa forma, recebe influências sociais, econômicas e culturais. Assim, como aponta Saviani (2011, p. 179), “[...] o planejamento da educação é, nas diferentes circunstâncias, um instrumento de política educacional, isto é, a forma pela qual se busca implementar determinada política que se preconiza para a educação.”

Nesse cenário, o Plano Nacional de Educação 2014-2024 assume caráter de política pública educacional e se refere ao agir e ao fazer, sobretudo com ações governamentais que são pensadas e implementadas no sistema educacional. Nessa perspectiva, expressase a multiplicidade e a diversidade da política educacional em um dado momento histórico.

A formação de professores no Brasil assume contornos substantivos no PNE e nas políticas educativas decorrentes, em face de sua complexidade, a qual envolve a formação inicial, oferecida em cursos de licenciatura, e a formação continuada, enquanto possibilidade de revitalizar e refletir a prática desenvolvida, e um maior desenvolvimento do profissional docente.

\section{O breve PNE e os rumos da formação docente}

Considerando todo o contexto histórico de (re)construção de um Plano Nacional de Educação, "iniciamos a segunda década do século XXI com um desafio da mais alta relevância para o futuro do Brasil [...] aprovar o Plano Nacional de Educação (PNE) como política de Estado para os próximos dez anos (2011-2020)" (ANPED, 2011, p. 483). Ao considerarmos os resultados alcançados pelo antigo Plano Nacional de Educação, percebemos a necessidade de prosseguir em muitos aspectos para garantir uma educação de qualidade.

Conforme Scheibe (2010, p. 982) “[...] o ponto de partida são os problemas já identificados e mesmo os avanços já conquistados; sobretudo, parte-se da certeza de que mesmo os avanços trazem novos desafios. Uma leitura daquilo que é hoje nos possibilita dizer com maior clareza o que se pretende para o futuro."

Ancorada pela legislação vigente, em especial a Constituição Federal de 1988 e a LDB, Lei 9.394/96, levou-se atermo no ano de 2010 a Conferência Nacional de Educação - CONAE, que, embora sendo organizada por iniciativa governamental - sociedade

${ }^{4}$ Quando a ANPED (2011) se refere a essa data, não havia sido aprovado o PNE, por isso se refere ao Plano de 2010-2020, que foi aprovado somente em 2014, pela Lei no 13.005. 
política, abriu espaço para a participação dos diferentes segmentos da comunidade educacional - sociedade civil (SAVIANI, 2011). Assim, a CONAE configurou-se em um processo de debate democrático e participativo, com o objetivo de definir os rumos da educação brasileira e colher subsídios para a elaboração do Plano Nacional de Educação (PNE) para dez anos.

A forma como foi elaborado o novo PNE diferencia-se de todos os outros, visto que foi aberto espaço de participação da sociedade civil para definir os rumos da educação brasileira. Ao final da CONAE foi elaborado um documento intitulado "Construindo o Sistema Nacional Articulado de Educação: o Plano Nacional de Educação, Diretrizes e estratégias de Ação", organizado em seis eixos que versam sobre todos os níveis da educação brasileira, com apontamentos para a elaboração do novo PNE. No entanto, um fato chamou a atenção. Participaram da organização ${ }^{5}$ da CONAE algumas entidades sindicais patronais que, certamente, não tinham nenhum interesse em comum com os estudantes, trabalhadores em educação e movimentos sociais (SARAIVA, 2011).

Sancionado pela Lei no 13.005 , de 25 de junho de 2014, destacamos ainda que o novo PNE 2014-2024 tem uma nova estrutura de organização em relação ao anterior, que era um documento de, aproximadamente, 100 páginas, com 25 metas. 0 atual PNE totaliza dez diretrizes, 20 metas, como estratégias para a política educacional de uma década. Conforme o documento "linha de base" publicado pelo MEC, em 2015, as metas estão subdivididas em grupos. 0 primeiro grupo são metas estruturantes para a garantia do direito à Educação Básica com qualidade, e, que assim promova a garantia do acesso à universalização do ensino obrigatório e à ampliação das oportunidades educacionais. Um segundo grupo de metas diz respeito, especificamente, à redução das desigualdades e à valorização da diversidade, caminhos imprescindíveis para a equidade. 0 terceiro bloco de metas trata da valorização dos profissionais da educação, considerada estratégica para que as metas anteriores sejam atingidas, e o quarto grupo de metas refere-se ao Ensino Superior. Segundo Hypolito (2015), em certos aspectos o PNE consegue expressar alguns anseios da comunidade educacional progressista e comprometida com a educação pública, o que constitui aspectos de seu avanço, no entanto, é paradoxal em alguns temas, ambíguo em outros, ora incompleto e deficiente em muitas temáticas.

\footnotetext{
${ }^{5}$ A Confederação Nacional dos Estabelecimentos de Ensino, a Confederação Nacional dos Empresários e a Confederação Nacional da Indústria fizeram parte da Comissão Organizadora da CONAE.
} 
A partir das proposições para a educação brasileira, previstas no PNE, a Educação Básica assume importância vital dentro da perspectiva de atender às exigências de uma sociedade em processo de busca pela democracia, que só terá êxito na medida em que os cidadãos tiverem acesso à informação, ao conhecimento e forem participantes efetivos das ações que dizem respeito à promoção humana e ao direito inalienável da cidadania e do exercício da democracia. Dessa forma, ressaltamos ainda, a necessidade da formação de qualidade para os profissionais da educação, dando atenção às metas do PNE que preveem recursos e incentivos para a profissionalização docente.

A efetiva aplicação do PNE 2014-2024, supunha-se, desencadearia um amplo movimento de renovação da educação, já que as metas e estratégias traçadas para os dez anos contemplam desafios históricos das diferentes etapas da Educação Básica e da formação dos profissionais da educação. No entender de Weber (2015) as políticas que culminam o PNE resultam de mais de quatro décadas de debates e proposições com vistas à formação e valorização profissional dos professores. As medidas adotadas pela CAPES, que passa a responder também pela formação do professor da educação Básica, criando uma Diretoria específica para isso, alimentavam nossa esperança que finalmente avançaríamos e atingiríamos as metas esperadas a este respeito, pois suas

[...] tônicas de ação se pautam pela formação de qualidade, integração entre pós-graduação, formação de professores e escola básica e produção de conhecimento, e correspondem ao debate educacional dos últimos 40 anos que tem integrado as dimensões relacionadas a trabalho e formação no sentido do que hoje é referido como valorização docente (WEBER, 2015, p. 508).

Poder-se-ia afirmar que o PNE 2014-2024 se apresenta como um plano ousado e um instrumento de luta, haja vista, o pressuposto de que esse PNE, enquanto política de Estado, preconiza as políticas de formação e valorização docente, contemplando discussões e diretrizes que vinham sendo propostas no meio acadêmico e como anseio da sociedade civil organizada. Dentre as vinte metas do Plano, quatro tratam, especificamente, da formação e da valorização docente, o que se constitui em avanço em relação aos planos anteriores. Tal fato, segundo Weber (2015, p. 509), concretiza a persistência "[...] da disputa pela fixação de determinados sentidos que possam dar materialidade à especificidade da ação docente a ser desenvolvida na perspectiva da educação como direito social básico e condição de exercício da cidadania." 
Este ensaio focaliza, portanto, as metas de $\mathrm{n}^{\mathrm{o}} \mathbf{1 5}, 16,17$ e 18 - na perspectiva de apresentar como a formação e a valorização docente estão proclamadas no Plano Nacional de Educação em vigor. 0 texto da meta 15 propõe:

[...] garantir, em regime de colaboração entre a União, os Estados, o Distrito Federal e os Municípios, no prazo de 1 (um) ano de vigência deste PNE, política nacional de formação dos profissionais da educação de que tratam os incisos I, II e III do caput do art. 61 da Lei no 9.394, de 20 de dezembro de 1996, assegurado que todos os professores e as professoras da educação básica possuam formação específica de nível superior, obtida em curso de licenciatura na área de conhecimento em que atuam.

A meta em tela destaca a obrigatoriedade de formação em nível superior, em cursos de licenciatura, por todos os professores da Educação Básica. Ao encontro dessa proposta preconiza a construção de uma política nacional de formação dos profissionais da educação, já no primeiro ano de vigência do Plano (levada a cabo em 25 de junho de 2015). Nas palavras de Scheibe (2016, p.1): “[... o documento que deverá gerir esta política nacional de formação, contudo, está ainda em discussão e pretende-se que seja finalizado em breve." A autora complementa, dizendo ainda que, "[...] o cenário é desafiador, se considerarmos o percentual expressivo dos professores brasileiros que ainda não tem a formação mínima requerida para o nível ou a disciplina em que atuam." (SCHEIBE, 2016, p. 1).

A regulamentação desta meta aconteceu através da Res.no 2/2015, que trata das Diretrizes para Formação de Professores no Brasil e que sofreu alteração no seu artigo 22, adiando de dois para três anos o tempo para sua implementação. Tal alteração deu-se pelo Parecer no 10/2017, de 10 de maio de 2017, do Conselho Nacional de Educação/Conselho Pleno. A justificativa para tal decisão foi embasada nas manifestações expressasjunto ao Ministério da Educação pela Associação Nacional dos Dirigentes das Instituições Federais de Ensino Superior (ANDIFES), pela Associação Brasileira das Universidades Comunitárias (ABRUC), pela Associação Catarinense das Fundações Educacionais (ACAFE) e pelo Fórum das Entidades Representantes do Ensino Superior Particular (FÓRUM), todas apresentando documentos e propondo ampliação do prazo. Diante das recentes medidas do governo federal percebemos que não foi casual seu aceite de prorrogação de prazo. 
Em relação a essa previsão, utilizamo-nos, também, dos indicadores fornecidos pelo Observatório do PNE $(2016)^{6}$, os quais apontam que em 2013 , apenas 74,8\% dos professores da Educação Básica possuem formação com Ensino Superior, o que significa que um quarto dos professores lecionavam mesmo sem ter formação no nível desejado. Deste percentual, apenas $65,4 \%$ detinham formação em cursos de licenciaturas. A formação inicial é essencial para embasar teoricamente e capacitar os profissionais em relação à sua prática docente. Importante destacar que essa formação necessita estar articulada aos processos de ensino e aprendizagem e na organização e gestão da Educação Básica. De nada adianta formar um professor distanciado do contexto socioeducacional em que, futuramente, irá atuar. Nóvoa (2007) tem reiterado em suas falas e escritos a respeito da necessidade do vínculo com a prática e com o cotidiano da escola como uma das alternativas necessárias para se qualificar a formação docente. Sob esse prisma, Oliveira (2011, p. 34) aponta que “[...] as políticas educacionais recentes no Brasil têm manifestado a necessidade de dedicar maior atenção ao magistério público para melhor responder às novas demandas apresentadas às escolas [...]"7.

0 cenário referente à formação docente no Brasil teve mudanças a partir da Lei de Diretrizes e Bases da Educação Nacional (LDB) de 1996, que estabeleceu a formação superior como condição para lecionar ${ }^{8}$ A oferta de cursos de graduação em Pedagogia e outras Licenciaturas, nos últimos anos, foi estimulada pelos programas e políticas de formação e financiamento como o PARFOR, PROUNI e FIES $^{9}$ que facilitaram a inserção e permanência em cursos de formação de professores. Tais Programas encontram descontinuidade na mudança das forças políticas do governo que sucedeu Dilma Roussef, seja em forma de reconfiguração, ou de redução significativa da aplicação de recursos.

\footnotetext{
${ }^{6} \mathrm{O}$ Observatório do PNE é uma plataforma online que tem como objetivo monitorar os indicadores referentes a cada uma das 20 metas do Plano Nacional de Educação (PNE) e de suas respectivas estratégias, e oferecer análises sobre as políticas públicas educacionais já existentes e que serão implementadas ao longo dos dez anos de vigência do Plano. Esses dados são resultado do Censo de 2013. Disponível em: <http://www.observatoriodopne.org.br/>

${ }^{7}$ Podemos fazer referência à Base Nacional Comum Curricular, prevista na Constituição para o ensino fundamental e ampliada no Plano Nacional de Educação, para o ensino médio, visando à renovação e ao aprimoramento da educação básica como um todo. Assume um forte sentido estratégico nas ações de todos os educadores, bem como gestores de educação do Brasil. Com efeito, a formação inicial e continuada dos professores muda sua estrutura e passa a seguir Diretrizes específicas.

${ }^{8}$ Embora seja desejável a formação superior, é admitida, como formação mínima para o exercício do magistério na educação infantil e nos 5 primeiros anos do ensino fundamental, a oferecida em nível médio, na modalidade normal. (Redação da Lei no 12.796, de 2013).

${ }^{9}$ Plano Nacional de Formação de Professores da Educação Básica; Programa Universidade para Todos e Fundo de Financiamento Estudantil. Importante atentar para a situação atual desses programas, o PARFOR foi revogado pelo Decreto no 8.752/2016, enquanto que o PROUNI e FIES passaram por atualização de suas regras, dificultando o ingresso e permanência dos estudantes no Ensino Superior.
} 
É inadiável qualificar o processo de formação inicial dos docentes enquanto condição fundamental e mínima para o exercício profissional. Tal perspectiva exige, atuação das Universidades em seus currículos, o que a Resolução no 02/2015, entre outros aspectos, parece contribuir.

Existem descompassos entre a formação universitária e a realidade encontrada em sala de aula, especialmente nos primeiros anos de profissão, que se tornam fundamentais para a sequência da carreira docente. Nóvoa (2007, p. 7) alerta a respeito da forma como realizamos a formação inicial, o que nela oportunizamos de experiências docentes e a forma como inserimos os jovens professores. Para ele é um problema dramático da organização da profissão: “[...] o modo como nos organizamos na escola, como nos organizamos com os colegas e como integramos os jovens professores. Se não for possível resolver isso, haverá muita dificuldade em resolver muito dos outros problemas que temos pela frente."

Como uma alternativa, cabe às universidades reverem seus currículos na busca de formar docentes que dominem os conhecimentos sobre o objeto de ensino, de modo que o aluno se aproxime dele e das condições didáticas, das intervenções e incursões na prática, necessárias ao seu avanço. Os cursos de licenciatura no país, carregam uma tradição disciplinar muito enraizada, o que impede a efetivação de uma formação vinculada à prática de escolarização (SCHEIBE, 2010).

Almejamos que a licenciatura desenvolva nos alunos os conhecimentos, as habilidades, as atitudes e os valores que possibilitem construir seus saberes e fazeres docentes para que possam desenvolver, com coerência, uma prática social. E que, a partir desses saberes e dessa prática, construam, de modo contínuo, a sua identidade e profissionalidade docente. Estas, segundo Nóvoa (2007, p. 9), construídas em comunhão estreita com a pessoalidade.

Na educação não é possível separar a dimensão da profissionalidade da dimensão de pessoalidade e isso implica em um compromisso pessoal, de valores, do ponto de vista da profissão. É nesse sentido que julgo que nós podemos e devemos caminhar no sentido de celebrar um novo contrato educativo com a sociedade, que passa também pela reformulação da profissão.

Construir uma identidade é um processo de ação do sujeito que está situado na história. A identidade profissional recebe influências da sociedade e da época em que o profissional está inserido, ou seja, das perspectivas de formação e de carreira profissional. Nesse sentido, Pimenta (2000, p.19) ensina que: “[...] uma identidade profissional se 
constrói, pois, a partir da significação social da profissão; da revisão das tradições. Mas também da reafirmação de práticas consagradas culturalmente e que permanecem significativas”. Em outro contexto mas, nos propósitos do estudo, Imbernón (2009, p. 75) pontua:

0 (re)conhecimento da identidade permite interpretar melhor o trabalho docente, interagir melhor com os outros, como contexto que se vive dia a dia nos centros, já que as experiências de vida do professorado se relacionam com as tarefas profissionais, já que o ensino requer um envolvimento pessoal. E a formação baseada na reflexividade será um elemento importante para analisar o que são ou que acreditam ser e o que se faz e como se faz.

É por meio de seu reconhecimento em relação à sua profissão que o professor conseguirá desenvolver o seu trabalho pedagógico com maior êxito e, a partir disso, criar um vínculo maior com a comunidade escolar. Nóvoa (2007) insiste que o professor precisa buscar seu espaço e fazer ouvir sua voz, pois o que se identifica é que nossas vozes estão ausentes. Quem fala sobre a educação, não poucas vezes, são outros atores e nós permanecemos calados. Quem tem maior autoridade para falar a respeito e sobre os dilemas da educação do que nós que a vivemos dia a dia em intensidade? Nossa credibilidade como categoria profissional passa por nos fazer ouvir e aprendermos a ter uma intervenção pública mais forte, mais crítica, mais decisiva em função da educação.

Creio que é essa voz que nos permite em parte ganhar esse espaço público da educação. Ganhar essa dimensão do apoio da sociedade ao trabalho da escola. É preciso ganhar a confiança da sociedade para o nosso trabalho, ganhar maior credibilidade pública. É preciso conquistar a sociedade para o nosso trabalho (NÓVOA, 2007, p. 9).

Interessa assinalar, ainda, que a valorização da pessoa do professor, as suas relações interpessoais contribuem para que a sua prática, realmente, obtenha sucesso. Com efeito, o envolvimento com os colegas de profissão colabora tanto para o seu trabalho, quanto para a sua vida pessoal. A identidade dos docentes e de qualquer outra profissão é uma construção que atravessa a vida profissional desde o momento da escolha da ocupação, estendendo-se pela formação inicial e pelos diferentes espaços institucionais nos quais se desenvolve e atua, profissionalmente, o que lhe confere uma dimensão no tempo e no espaço.

Decorridos três anos da vigência do PNE e em face ao quadro dramático de retrocessos de conquistas há muito desejadas, da ausência de espaços de diálogo e de interlocutores, as metas previstas podem se constituir em mais um discurso vazio. 
Veja-se a meta 16:

Formar, em nível de pós-graduação, 50\% (cinquenta por cento) dos professores da educação básica, até o último ano de vigência deste PNE, e garantir a todos (as) os (as) profissionais da educação básica formação continuada em sua área de atuação, considerando as necessidades, demandas e contextualizações dos sistemas de ensino.

Atualmente, apenas 30\% dos professores da Educação Básica possuem PósGraduação, segundo dados do Censo Escolar (2014). As lacunas na formação inicial dos docentes é um dos grandes entraves na melhoria da qualidade da educação. Compreendemos a formação continuada como uma possibilidade de reflexão e de desenvolvimento profissional docente e não compensatória de fragilidades da formação inicial. Para que tal formação se efetive é essencial sobretudo, considerar as especificidades de cada local/escola e corpo docente.

O professor, através de seus conhecimentos, dos saberes, das suas competências e habilidades, dá sentido à sua prática e à sua identidade. Nóvoa (2017, p. 5-6) insiste que um dos atributos fundamentais com qual o professor deve ser identificado é pelo conhecimento. A base de sustentação do professor é o conhecimento. "A nossa matériaprima é o conhecimento, mas o trabalho pedagógico só termina quando esse conhecimento é objeto de apropriação por um sujeito."

Os docentes devem ser reconhecidos como sujeitos que possuem, utilizam e produzem saberes específicos ao seu ofício, ao seu trabalho. Eles ocupam na escola uma posição fundamental em relação ao conjunto dos agentes escolares, pois é sobre eles que recai a responsabilidade no que diz respeito à missão educativa da escola. Com efeito:

[...] observa-se, hoje grande pressão para que os professores apresentem melhor desempenho, principalmente no sentido de os estudantes obterem melhores resultados nos exames nacionais e internacionais. As críticas ressaltam, sobretudo, os professores como malformados e pouco imbuídos de sua responsabilidade pelo desempenho dos estudantes (SCHEIBE, 2010, p. 985).

A formação continuada faz-se necessária para possibilitar a (re)construção da identidade profissional, bem como para renovar os saberes docentes, para que esses possam servir de subsídios para o aperfeiçoamento de sua prática em sala de aula. Nesse sentido, é fundamental que os responsáveis pelas políticas públicas de oferta dos cursos de formação continuada levem em consideração o fato de que cada contexto possui as suas especificidades e, portanto, os temas abordados não devem ser generalizados, eis 
que para despertar o interesse dos docentes pela formação continuada há que construir com os docentes e não para os docentes.

Nessa perspectiva, é necessário repensar a formação continuada, reestruturá-la de modo que incentive os professores a participar, ativamente, desse novo processo de aprendizagem. Quem sabe ousemos pensar em desenvolvimento profissional docente. Este não tem sido muito discutido e proposto no Brasil, mas na Espanha, Portugal e outros países há debates bem consolidados sobre essa ideia com o intuito de que a formação continuada esteja inserida em um percurso profissional, o que consideraríamos mais adequada. Assumir a perspectiva do desenvolvimento profissional vem ao encontro de uma formação dinâmica, em constante atualização e inovação, permitindo sua repercussão nos projetos educacionais, nos quais estão envolvidos professores e instituições. Segundo Marcelo Garcia (2009) o desenvolvimento profissional seria um processo que se vai construindo à medida que os docentes ganham experiência, sabedoria e consciência profissional, no qual a identidade profissional vai se configurando por meio dos processos de mudança e melhoria da profissão docente.

Repensar as políticas de valorização que implicam em salários dignos, plano de carreira com clareza de percurso que motivem o coletivo ao exercício da profissão, é jargão amplamente debatido. "Revela-se um cenário que exige assumir prioridades para tornar a ocupação não apenas mais atrativa e valorizada, mas também mais competente para o desenvolvimento de uma educação com qualidade para todos" (SCHEIBE, 2010, p. 985).

Geralmente, ausente dos manuais e prescrições relativas à formação docente, o PNE, aponta uma meta exclusiva para a valorização salarial, assim explicitada:

Valorizar os (as) profissionais do magistério das redes públicas de educação básica, de forma a equiparar seu rendimento médio ao dos (as) demais profissionais com escolaridade equivalente, até o final do sexto ano de vigência deste PNE.

Valorizar o campo profissional é o propósito daLei n 11.738 , sancionada em 16 de julho de 2008, que instituiu o piso salarial profissional nacional ${ }^{10}$ para os profissionais do magistério público da Educação Básica, inclusive questionando sua inconstitucionalidade. Embora permaneça vigente e conte com atualização anual, poucos Estados consideram

\footnotetext{
${ }^{10}$ Ainda que esta meta pareça alvissareira no momento que se redige este ensaio, os docentes do Estado do RS completam o 1ํㅡês de paralisação por conta de 21 meses de salário parcelado. Mais grave, a situação do RJ cujo funcionalismo amarga meses sem remuneração.
} 
suas determinações na remuneração docente. Entendemos que o PNE, configura-se numa política de estado que tem como uma das suas tarefas primordiais a articulação entre a formação inicial e continuada às políticas de valorização e carreira docente. A valorização salarial é uma opção política mais do que técnica ou administrativa. Tais questões são indissociáveis. "Ao lado de estratégias e políticas consistentes, coerentes e contínuas de formação inicial e continuada dos professores, precisam ser melhoradas as suas condições de trabalho, de carreira e de remuneração" (SCHEIBE, 2016, p. 987).

Para dar conta deste repto, a meta 18 avança no sentido de:

Assegurar, no prazo de 2 (dois) anos, a existência de planos de carreira para os (as) profissionais da educação básica e superior pública de todos os sistemas de ensino e, para o plano de carreira dos (as) profissionais da educação básica pública, tomar como referência o piso salarial nacional profissional, definido em lei federal, nos termos do inciso VIII do art. 206 da Constituição Federal.

Fica explícito, de certa forma, que pelo menos, no aporte legal, o documento busca assegurar maiores direitos e garantias aos professores da Educação Básica pública. Mas a relação entre o plano legal e o que acontece na prática, há contradições como aponta Oliveira (2011) na operacionalização são os estados e municípios que precisam dar conta da exigência legal, sem aporte de ercurso.

Responsabilizaro professor pelo sucesso ou insucesso escolar tem sido constante. Em que pese, a responsabilização do professor nos resultados dos seus alunos, há que denunciar essa forte tendência, na medida em que, esconde-se, muitas vezes, as condições sociais dos alunos e de trabalho dos professores.

\section{Considerações Finais}

É imprescindível compreender a educação enquanto política pública, articulada às demais políticas para que se fortaleça enquanto política de Estado. Condição que só se efetiva numa sociedade democrática.

Tal horizonte parece nebuloso ao se considerar o atual quadro político vivenciado e que ocasionou o desmonte de políticas exitosas, num claro retrocesso ao desempoderar as ações do coletivo docente, de suas entidades representativas e dos movimentos sociais progressistas, quando da centralização e gerencialismo das decisões políticas junto à instâncias do governo federal e pela construção de políticas por experts, burocratas ou 
pequenos grupos de intelectuais recrutados pelo governo, ignorando o histórico de debates e participação da sociedade brasileira.

Será possível avançar numa política educacional que busque a qualidade referenciada no breve PNE? São planos de carreira, salários atrativos, condições de trabalho adequadas, processos de formação inicial e continuada não para atender a mecanismos de regulação e avaliação, mas voltadas para o enriquecimento da prática educativa e formas criteriosas de seleção são requisitos para a definição de uma equipe de profissionais com o perfil necessário à melhoria da qualidade da Educação Básica pública, continuam sendo narrativas replicadas ad nauseam.

O novo PNE poderia assumir papel de protagonista no planejamento da educação brasileira e superar sua trajetória de documento formal. Vale aqui a máxima de Hypolito (2015) quando afirma que é uma luta por hegemonia, por controle de significados, por controle do sentido das políticas. O PNE pode ser o que está sendo ou o que queiramos que seja. Enquanto Estado federativo, assumir, verdadeiramente, essa caraterística, tendo o PNE como base para pensar, implantar, articular e concretizar políticas públicas que apontem soluções para os desafios da educação brasileira. Para isso, União, Estado e Municípios precisam desenvolver mecanismos de resistência à Emenda Constitucional noㅡ 55/2016 ou produziremosuma década perdida para a educação brasileira.

\section{Referências}

ANPED. Por um Plano Nacional de Educação (2011-2020) como política de Estado. RJ: Armazém das Letras, 2011.

BRASIL. CONAE 2010. Conferência Nacional de Educação. Construindo o Sistema Nacional Articulado de Educação: o Plano Nacional de Educação, diretrizes e estratégias. Documento Final. Brasília/DF: MEC, 2010. Disponível em: <https://goo.gl/BsR5C9> Acesso em: 03 jan. 2016.

Constituição (1988). Constituição da República Federativa do Brasil. Brasília/DF: Senado, 1988. Disponível em: <https://goo.gl/TNDgbw> Acesso em: 04 jan. 2016.

Decreto n.8.752, de 9 de maio de 2016. Dispõe sobre a Política Nacional de Formação dos Profissionais da Educação Básica. Disponível em: <https://goo.gl/3BfV3E>. Acesso em: 01 jun. 2016.

Emenda Constitucional 59/2009. Diário Oficial da União, Brasília/DF, 12 nov. 2009. Disponível em: <https://goo.gl/YPtVNu>. Acesso em: 04 jan. 2016.

Lei n.10.172/01, de 09 de janeiro de 2001. Aprova o Plano Nacional de Educação - PNE e dá outras providências. Diário Oficial da União, Brasília/DF, 10 jan. 2001. Disponível em: <https://goo.gl/Fmq3PT> Acesso em: 15 dez. 2015. 
Lei n.11.738/96, de 16 de julho de 2008. Regulamenta a alínea "e" do inciso III docaputdo art. 60 do Ato das DisposiçõesConstitucionais Transitórias, para instituir o piso salarial profissional nacional para os profissionais do magistério público da educação básica. Diário Oficial da União, Brasília, 17 jul. 2008. Disponível em: <https://goo.gl/tJKKEV> Acesso em: 10 dez. 2015.

Lei n.13.005/14, de 25 de junho de 2014. Aprova o Plano Nacional de Educação - PNE e dá outras providências. Diário Oficial da União, Brasília/DF, 26 jun. 2014, p.1, Edição Extra. Disponível em: <https://goo.gl/FJdtKy> Acesso em: 30 dez. 2015.

Lei n.9.394/96, de 20 de dezembro de 1996. Estabelece as diretrizes e bases da educação nacional. Diário Oficial da União, Brasília/DF, 23 dez. 1996, p.27894.

Planejando a próxima década: conhecendo as 20 metas do Plano Nacional de Educação. Brasília: Ministério da Educação/ Secretaria de Articulação com os Sistemas de Ensino (MEC/ SASE), 2014. Disponível em: <https://goo.gl/65dG3M> Acesso em: 04 jan. 2016.

Plano Nacional de Educação PNE 2014-2024: linha de base. Brasília: Presidência da República Federativa do Brasil/ Ministério da Educação - MEC/Secretaria Executiva/Instituto Nacional de Estudos e Pesquisas Educacionais Anísio Teixeira Inep/Diretoria de Estudos Educacionais - Dired, 2015. Disponível em: <https://goo.gl/8HYHqk> Acesso em: 30. dez. 2015.

Resolução n.2, de 1 de julho de 2015. Define as Diretrizes Curriculares Nacionais para a formação Inicial em nível superior e para a formação continuada dos profissionais da educação básica. Diário Oficial da União, Brasília/DF, 02 de jul. de 2015. Seção 1, p.812.

CONFERENCIA NACIONAL DA EDUCAÇÃO (CONAE), 2010, Brasília/DF. Documento final. Brasília/DF: MEC, 2010. Disponível em: <https://goo.gl/sjbA4g> Acesso em: Jan. 2016.

CONFERENCIA NACIONAL DA EDUCAÇÃO (CONAE), 2014, Brasília/DF. Documento final. Brasília/DF: MEC, 2015. Disponível em: <https://goo.gl/k2WfZd> Acesso em: jan. 2016.

MARCELO GARCIA, C. Desenvolvimento Profissional Docente: passado e futuro. Sísifo: Revista de Ciências da Educação, n.8, p.7-22, jan./abr., 2009.

DIAS, R.; MATOS, F. O conceito de política pública. In: DIAS, R.; MATOS, F. Políticas públicas: princípios, propósitos e processos. São Paulo: Atlas, 2012. p.1-19.

DOURADO, L.F. Avaliação do Plano Nacional de Educação 2001-2009: questões estruturais e conjunturais de uma política. Educação \& Sociedade, Campinas, v.31, n.112, p.677-705, jul./set. 2010.

Diretrizes curriculares nacionais para a formação inicial e continuada dos profissionais do magistério da educação básica: concepções e desafios. Educação \& Sociedade, Campinas, v.36, n.131, p.299-324, abr./jun. 2015.

Plano Nacional de Educação como Política de Estado: antecedentes históricos, avaliação e perspectivas. In: DOURADO, Luiz Fernandes (Org.). Plano Nacional de Educação (2011-2020): avaliação e perspectivas. Goiânia: UFG, 2011. p.17-59. 
HYPOLITO, Á.L.M. Trabalho docente e o novo Plano Nacional de Educação: valorização, formação e condições de trabalho. Cad. Cedes. Campinas, v.35, n.97, p.517-534, set./dez., 2015.

LEÃO, R. A valorização dos profissionais da Educação como pilar da qualidade. In: Confederação Nacional dos Trabalhadores em Educação em 01/06/2013. Disponível em: <https://goo.gl/1eV4N7> Acesso em: 07 jan. 2016.

NÓVOA, A. Desafios do trabalho do professor no mundo contemporâneo. Palestra SINPRO. Porto Alegre: Janeiro de 2007.

Pedagogia: a terceira margem do rio. Disponível em: <www.iea.usp.br/textos> Acesso em: 28 out. 2016.

OLIVEIRA, D.A. Das políticas de governo à política de estado: reflexões sobre a atual agenda educacional brasileira. Educação e Sociedade, Campinas, v.32, n.115, p.323-337, abr-jun. 2011.

SARAIVA, C. Novo PNE: uma sistematização da contra reforma do ensino superior. CSPConlutas - Central Sindical e Popular. 03/05/2011. Disponível em: <http://www.pstu.org.br/node/16328 > Acesso em: 05 jan. 2016.

SAVIANI, D. Da nova LDB ao FUNDEB: por uma outra política educacional. 4ed. Campinas/SP: Autores Associados, 2011.

Sistema Nacional de Educação e Plano Nacional de Educação: significado, controvérsias e perspectivas. Campinas: Autores Associados, 2014.

SCHEIBE, L. O Processo de Formação Docente no Brasil. Site URI -FredericoWestphalen, 27 abr. 2016. p.1-2. Entrevista.

Valorização e formação dos professores para a educação básica: questões desafiadoras para um novo plano nacional de educação. Educação e Sociedade, Campinas, v.31, n.112, p.981-1000, jul./set. 2010.

WEBER, S. O Plano Nacional de Educação e a valorização docente: confluência do debate nacional. Cad. Cedes. Campinas, v.35, n.97, p.495-515, set./dez., 2015. 


\section{JORNAL DE POLÍTICAS EDUCACIONAIS}

ISSN 1981-1969

Volume 12

Número 4

28 de fevereiro de 2018

\section{SOCDE RIGHIS RESERNED}

Copyright é retido pelo/a autor/a (ou primeiro co-autor) que outorga o direito da primeira publicação ao Jornal de Políticas Educacionais. Mais informação da licença de CreativeCommons encontram-se em http://creativecommons.org/licenses/by-nc-nd/2.5. Qualquer outro uso deve ser aprovado em conjunto pelo/s autor/es e pelo periódico.

JoRnal DE PolíticAs EduCACIONAIS é uma publicação do Núcleo de PolíticasEducacionaisdo Setor de Educação da Universidade Federal do Paraná - NuPE/UFPR, em consórcio com a Linha de Pesquisa em Políticas Educacionais do Programa de Pós-Graduação em Educação - PPGE/UFPR, que aceita colaboração, reservando-se o direito de publicar ou não o material espontaneamente enviado à redação. As colaborações devem ser enviadas ao NuPE/UFPR, conforme orientações contidas nas páginas do periódico na internet: http://revistas.ufpr.br/jpe.

Indexação:

BBE - Biblioteca Brasileira de Educação (MEC/INEP)

Clase (Base de Datos Bibliográfica de Revistas de Ciencias Sociales y Humanidades)

Diadorim - Diretório de Política de Acesso Aberto das Revistas Científicas Brasileiras (IBICT)

Google Scholar

Index Copernicus

Portal de Periódicos (CAPES)

SER - Sistema Eletrônico de Revistas da Universidade Federal do Paraná (SER/UFPR)

Sumários de Revistas Brasileiras (FUNPEC-RP)

DRII - Directory of Research Journals Indexing

(Periódico integralmente disponível apenas em via eletrônica)

Jornal de Políticas Educacionais / Núcleo de Políticas Educacionais da Universidade Federal do Paraná NuPE/UFPR - v.1, n. 1 (1ํㅗ semestre de 2007) - Curitiba: NuPE/UFPR.

Volume 12, número 4 - Fevereiro de 2018

ISSN 1981-1969

1. Educação - Periódicos. 2. Política Educacional - Periódicos. I. NuPE/UFPR

Comitê Editorial:

Ângelo Ricardo de Souza (UFPR)

Ana Lorena Bruel (UFPR)

Marcos Alexandre Ferraz (UFPR)

Conselho Editorial:

Andréa Barbosa Gouveia (UFPR), Ângela Hidalgo (UNICENTRO), Cesar GernominoTello (Universidad Nacional TresFebrero, Argentina),Gladys Beatriz Barreyro (USP), Juca Gil (UFRGS), Jefferson Mainardes (UEPG), João Ferreira de Oliveira (UFG), Luiz Souza Júnior (UFPB), Marcos Edgard Bassi (UFSC), Regina 
Maria Michelotto (UFPR), Robert Verhine (UFBA), Rosana Cruz (UFPI), Rubens Barbosa Camargo (USP), Sebastián Donoso Díaz (Universidad de Talca, Chile), Taís Moura Tavares (UFPR), TheresaAdrião (UNICAMP), Vera Peroni (UFRGS).

Jornal de Políticas Educacionais

Universidade Federal do Paraná

Setor de Educação

Núcleo de Políticas Educacionais - NuPE/UFPR

Rua Gal. Carneiro, 460 - 40 andar - Sala 407/C

80.060-150 - Curitiba - PR - Brasil

Tel.: 41-3360-5380

jpe@ufpr.br

http://revistas.ufpr.br/jpe 